\title{
Clinicopathological pattern of benign breast diseases among female patients at a tertiary health institution in Tanzania
}

\author{
PHILLIPO L. CHALYA ${ }^{1 *}$, MANGE MANYAMA ${ }^{2}$, PETER F. RAMBAU ${ }^{3}$, ANTHONY KAPESA ${ }^{4}$, SOSPATRO E. \\ NBALLABA ${ }^{4}$, NESTORY MASALU ${ }^{5}$ and JOSEPH B. MABULA ${ }^{1}$ \\ ${ }^{1}$ Department of Surgery, Catholic University of Health and Allied Sciences-Bugando, Mwanza, Tanzania \\ ${ }^{2}$ Department of Anatomy, Catholic University of Health and Allied Sciences-Bugando, Mwanza, Tanzania \\ ${ }^{3}$ Department of Pathology, Catholic University of Health and Allied Sciences-Bugando, Mwanza, Tanzania \\ ${ }^{4}$ Institute of Public Health, Catholic University of Health and Allied Sciences-Bugando, Mwanza, Tanzania \\ ${ }^{5}$ Department of Oncology, Catholic University of Health and Allied Sciences-Bugando, Mwanza, Tanzania
}

\begin{abstract}
Background: Benign breast diseases are a neglected entity in developing countries despite the fact that they constitute the majority of breast complaints. There is a paucity of published information regarding benign breast diseases in Tanzania. This study describes our experience in the management of benign breast diseases outlining the clinicopathological pattern and treatment modalities of these diseases in our local setting.

Methods: This prospective descriptive study was conducted between November 2009 and March 2013 at Bugando Medical Centre in Tanzania on female patients aged 10 years and above presenting with benign breast diseases.

Results: A total of 346 female patients with benign breast diseases were studied. The majority of patients, 255 (73.7\%) were younger than 30 years. Breast lump was the most frequent presentation in $67.6 \%$ of patients. Fibroadenoma $95(60.0 \%)$ was the most frequently diagnosed benign breast disease followed by fibrocystic changes (19.0\%). Out of 295 patients who had histopathological examination, 64 (21.7\%) had proliferative lesions. Of these, 18 (28.1\%) had proliferative lesions with atypia while $46(71.9 \%)$ had proliferative lesions without atypia. Eight (2.6\%) patients were HIV positive with the median CD 4+ Count of 258 cells/ $\mu$ l. The majority of patients, $295(85.2 \%)$ underwent surgical treatment of which lumpectomy was the most common procedure performed.

Conclusion: Benign breast diseases are more common than malignancies in our environment and occur mainly in young women less than 30 years of age and were mostly fibroadenoma and fibrocystic change. Though premalignant lesions of proliferative lesions with atypia were less common in this study, it is advisable that all cases of breast lesions should be carefully evaluated to exclude possibility of breast cancer.
\end{abstract}

Keywords: breast diseases, clinicopathological, patterns, management, Tanzania

\section{Introduction}

Benign breast diseases which form the majority of breast diseases constitute a spectrum of lesions ranging from developmental abnormalities, inflammatory lesions, epithelial and stromal proliferations to various neoplasms (Tavassoli \& Devilee, 2003; Guray \& Sahin, 2006; Khanzada et al, 2009). They are the most common cause of breast problems in females and they are more frequent than the malignant ones (Khemka et al., 2009). Benign breast diseases are at least 10 times more common than breast cancer in developed countries (Mansell, 1992; Krishnaswamy., 2003). Globally, benign breast diseases are the most common lesions accounting for $90 \%$ of the clinical presentation related to breast (Murillo, 2002; Pollitt \& Gateley, 2004). In Uganda, Trinidad and Nigeria, benign breast diseases constitute $70-79 \%$ of breast lesions (Raju \& Naraynsingh, 1985; Olu-Eddo et al., 2011; Echejoh et al., 2011). Fibroadenoma, fibrocystic change and breast abscesses

\footnotetext{
* Correspondence: E-mail: drphillipoleo@yahoo.com
} 
account for most of these benign lesions in most studies in developing countries (Olu-Eddo et al., 2011; Echejoh et al., 2011).

Benign breast diseases are primarily seen in women of reproductive age and thought to be largely hormonally induced (Hutter, 1985; Devitt, 1986). The incidence of benign breast diseases begins to rise during the second decade of life and peaks in the fourth and fifth decade (Donegan, 2002; Shaaban et al., 2002; Okoth et al., 2013). The most common symptoms are pain and palpable breast lumps. Other clinical features include nipple discharge, nipple deformity such as retraction and occasional skin changes (dermatitis in some form of mastitis as well as dimpling in fat necrosis and fibrosis) (Echejoh et al., 2011; Okoth et al., 2013). The diagnosis of benign breast disease can be achieved with the use of mammography, ultrasound, magnetic resonance imaging, fine needle biopsies and incision or excision biopsies (Echejoh et al., 2011). The triple assessment consisting of clinical evaluation, breast imaging and fine needle aspiration cytology (FNAC) has been recommended as a diagnostic tool for evaluation of patients with palpable breast lumps (Hught et al., 1998; Mande et al., 2004). When the three assessments are performed adequately and produce concordant results, the triple assessment diagnostic accuracy approaches $100 \%$ and definitive treatment can be started before histology (Hught et al., 1998; Mande et al., 2004). The treatment of breast disease in the developing countries poses a major challenge due to late presentation because of illiteracy, social taboo, unawareness resulting in delay in diagnosis, especially in malignancy as well as in benign lumps in breast (Olu-Eddo et al., 2011).

Benign lesions of the breast have assumed increasing importance in recent years because of the public awareness of breast cancer (Echejoh et al., 2011; Olu-Eddo et al., 2011; Okoth et al., 2013). These benign diseases are a recognized important risk factor for later breast cancer which can develop in either breast (Olu-Eddo et al., 2011). While most reports indicate that breast lumps are predominantly benign and mostly nonproliferative epithelial lesions, there has, however, been an increasing recognition of the risk of developing cancer from the various forms of premalignant lesions, especially atypical ductal and atypical lobular hyperplasia (Okoth et al., 2013). Women with benign proliferative or atypical breast lesions have a two-fold risk of developing breast cancer in western populations (Okoth et al., 2013). It is therefore important for surgeons, pathologists and oncologists to recognize benign lesions, both to distinguish them from in situ and invasive breast cancer and to assess a patient's risk of developing breast cancer, so that the most appropriate treatment modality for each case can be established (Guray \& Sahin, 2006).

Benign breast diseases are a neglected entity despite the fact that it constitutes the majority of breast complaints (Srivatsava \& Dhar, 2006). Breast cancer has taken precedence over benign breast disease since it is more fearsome although the number of females with benign breast diseases is substantial (Abhijit et al., 2013). Consequently, many patients with benign breast diseases receive little attention from clinicians. There is a paucity of information regarding benign breast diseases in Tanzania and particularly in north-western region. This is partly due to a lack of published local data regarding these conditions in this region. This study was designed to describe the clinicopathological pattern of benign breast diseases and highlight our experience in the management of these diseases.

\section{Materials and Methods}

\section{Study design and setting}

This prospective descriptive study was conducted between November 2009 and March 2013 at Bugando Medical Centre on female patients aged 10 years and above presenting with benign breast diseases. Bugando Medical Centre is a 1000 bed referral hospital located in Mwanza city in north-western Tanzania on the southern border of Lake Victoria. It is also a teaching hospital for the Catholic University of Health and Allied Sciences (CUHAS). The hospital serves a population of 
approximately 13 million people from neighbouring regions in north-western Tanzania. More than $50 \%$ of this population seeks service from this hospital.

\section{Study population and procedures}

The study population included all female patients aged 10 years and above who presented to the surgical outpatient clinic of Bugando Medical Centre with benign breast diseases. Patients with obvious clinical features of malignancy or those who on work up were diagnosed as carcinoma were excluded from the study. Detailed history of patients were recorded that included age, marital status, parity, age of menarche, age at first pregnancy and age at menopause. Patients aged 50 years or above and having no menses for at least two years at the time of presentation were considered to be postmenopausal. Family history of breast diseases especially breast cancer, history of contraception used was recorded. Detailed examination of lump and axilla was made with especial attention to any clinical signs of malignancy. Ultrasonography or mammograms were done when required necessary. Fine needle aspiration cytology (FNAC) was performed in patients with lumps to confirm the diagnosis. Core biopsy and / incisional or excision biopsy was done in patients with inconclusive FNAC report.

All recruited patients were managed accordingly. The investigators ensured that the study patients were receiving the appropriate treatment as prescribed by the surgeon. The majority of patients were managed as outpatients at the surgical outpatient clinic. Patients who underwent surgical treatment were admitted for a day or two and then discharged home. After discharge patients were followed up at the surgical outpatient clinic for up to three months and then discharged from clinic depending on type of diagnosis. This information was entered in a predesigned form and frequencies of various benign breast diseases in different age groups were calculated.

\section{Data analysis}

Data analysis was done using SPSS software version 17.0 (SPSS, Inc, Chicago, IL, USA). Data was summarized in form of proportions and frequency tables for categorical variables whereas continuous variables were summarized using median and ranges. Chi-square $\left(\chi_{2}\right)$ test was used to test for significance of associations between the predictor and outcome variables in the categorical variables) whereas independent student $t$-test was used in continuous variables. Odds ratio (OR) was calculated to test for strength of association between predictor variables. Multivariate logistic regression analysis was used to determine predictor variables that are associated with outcome. Significance was defined as a p-value of less than 0.05 .

\section{Ethical consideration}

Ethical clearance to conduct the study was obtained from the CUHAS/BMC Joint Institutional Ethic Review Committee before the commencement of the study. Informed consent was sought from each patient before being enrolled into the study. In patients younger than 18 years, informed consent was sought from parents or relative on behave.

\section{Results}

Out of 438 patients who presented to our centre with breast diseases during the study period, $352(80.4 \%)$ had benign breast disease and 86(19.6\%) had malignant breast disease with a benign to malignant ratio of 4.1: 1. Of the 352 patients with benign breast disease, 346 were eligible for the study and 6 were excluded due to incomplete data and failure to meet the inclusion criteria. Patients with malignant breast diseases were also excluded from the study. Thus, a total of 346 female patients with benign breast diseases were studied. The age of patients at presentation ranged from 14 to 72 years with a median age of 26 (+IQR of 23 to 32 ) years. The modal age group was $21-30$ years accounting for $69.9 \%$ of patients. The majority of patients, 255 (73.7\%) were 
younger ( $\leq 30$ years). Of the 346 patients, 324 (93.6\%) were premenopausal, 246 (71.1\%) were single and 92 (26.6\%) were married, 202(58.4\%) were nulliparous, 74(21.4\%) had been breast feeding. The median age at menarche was 13 (+ IQR of 9 to 15) years. History of contraceptive use was reported in $98(28.3 \%)$. Past history of breast disease was reported in 16 (4.6\%) patients. Family history of breast disease was positive in 29 (8.4\%) patients.

The duration of symptoms before presentation ranged from 3 days to 48 months with an overall median duration of 4 months (+IQR of 2 to 6 months). The median time interval between onset of symptoms and presentation at the surgical outpatient clinic was 2 weeks, 3 months and 1 week for breast pain, breast lump and nipple discharge, respectively. The reasons for the delay in presentation are presented in Table 1.

Table 1: Distribution of patients according to the reason for late presentation when with breast lumps

\begin{tabular}{lll}
\hline Reasons for late presentation & Frequency & Percentages \\
\hline Financial constraints & 184 & 53.2 \\
Painless lump & 102 & 29.5 \\
Lump might disappear & 56 & 16.2 \\
Delayed referral to tertiary care facility & 34 & 9.8 \\
Lump does not interfere with normal duties & 30 & 8.7 \\
Lack of awareness about the disease & 26 & 7.5 \\
No reason given & 38 & 11.0 \\
\hline
\end{tabular}

Breast lump was the most frequent presentation in $67.6 \%$ of patients (Table 2 ). The breast lumps associated with other symptoms such as breast pain or nipple discharge or both was reported in 43(12.4\%) patients. The breast lump size ranged from 0.5 to $18 \mathrm{~cm}$ with a median diameter of 6 $\mathrm{cm}$. The majority of patients (73.9\%) had breast lump of $6 \mathrm{~cm}$ diameter and below. The majority of breast lumps were located on the outer upper quadrant, 169 (63.5\%) followed by the inner lower quadrant, 35(13.2\%), outer lower quadrant, 24(9.0\%) and inner upper quadrant, $18(6.8 \%)$.

Table 2: Distribution of patients according to clinical presentations

\begin{tabular}{lll}
\hline Clinical presentation & Number of patients & Percentages \\
\hline Breast lump only & 234 & 67.6 \\
Breast pain only & 51 & 14.7 \\
Breast lump and breast pain & 25 & 7.2 \\
Breast lump and nipple discharge & 11 & 3.2 \\
Breast lump, breast pain and nipple discharge & 7 & 2.0 \\
Nipple discharge only & 7 & 2.0 \\
Other rare presentation such as nipple deformity, skin changes & 12 & 3.5 \\
Total & 346 & 100
\end{tabular}

Among $83(24.0 \%)$ patients with breast pain, 51 (14.7\%) complained of breast pain (mastalgia) only and these were treated by using a conservative approach or reassurance. The rest had associated complaints like breast lumps and nipple discharges. In patients who had mastalgia, the pain was cyclical in $38(74.5 \%)$ and non-cyclical in $13(25.5 \%)$ patients. Of the $25(7.2 \%)$ patients with nipple discharges, 7 (2.0\%) had nipple discharge only, without any associated lump or pain. The nipple discharge was blood in $13(52.0 \%)$ cases and it was milky and serosanguinous fluid in $7(28.0 \%)$ and 4(16.0\%) patients, respectively, and only one (4.0\%) had a yellow discharge. The right breast was more involved (53.8\%) than the left breast in (42.8\%). Bilateral breast lesions were found in 12 (3.4\%) patients.

Of the 346 patients with benign beast diseases, 302 (87.3\%) accepted to test for HIV infection. Of these, 8 (2.6\%) were found to be HIV positive. Out of the HIV positive patients, one (12.5\%) was a known case on anti-retroviral therapy (ARV) and the remaining 7 (87.5\%) were newly diagnosed patients. The CD 4+ count among HIV positive patients was available in only 7 patients and ranged from $120-730 \mathrm{cells} / \mu \mathrm{l}$ with the median of $258 \mathrm{cells} / \mu \mathrm{l}$ (+IQR of 242 to $264 \mathrm{cells} / \mu \mathrm{l}$ ). Two 
(28.6\%) HIV positive patients had CD4+ count below 200 cells/ $\mu$ land the remaining 5 (71.4\%) patients had CD4+ count of $\geq 200$ cells $/ \mu$ l.

In this study, breast ultrasonography was performed in $132(38.2 \%)$ patients and revealed abnormal findings in 120(91.0\%) patients. Mammography was performed in $64(18.5 \%)$ patients aged 35 years and above. FNAC was performed in $98(28.3 \%)$ patients. Triple assessment before definitive surgery was performed in only 48 (13.9\%) patients. In the present study, histopathological examination was performed in 295 (85.3\%) patients. Of these, fibroadenoma 95(60.0\%) was the most frequently diagnosed benign breast disease followed by fibrocystic changes in 56(19.0\%) patients (Table 3). Amongst the eight HIV positive patients, four had tuberculous benign breast disease, two had breast abscess, and one had ductal papillomas and duct ectasia each, respectively.

Of the 295 patients with benign breast lesions, $21.7 \%$ had proliferative lesions and $78.3 \%$ had non-proliferative lesion. Twenty-two (34.4\%) patients of those with benign proliferative breast lesions had been using hormonal contraception, while $42(65.6 \%)$ did not use hormonal contraception. This difference was statistically significant in multivariate regression analysis $(p=$ 0.002). Of the 64 benign proliferative breast lesions, $18(28.1 \%)$ had proliferative lesions with atypia while $46(71.9 \%)$ had proliferative lesions without atypia.

Table 3: Distribution of histopathological pattern versus age group

\begin{tabular}{lllllll}
\hline Histopathological pattern & \multicolumn{2}{l}{ Age group (in years) } & & & \\
\cline { 2 - 5 } & $<\mathbf{2 0}$ & $\mathbf{2 1 - 3 0}$ & $\mathbf{3 1 - 4 0}$ & $\mathbf{4 1 - 5 0}$ & $\mathbf{7 5 0}$ & Total \\
\hline Fibroadenoma & $6(2.0)$ & $152(51.5)$ & $15(5.1)$ & $4(1.4)$ & 0 & $177(60.0)$ \\
Fibrocystic diseases & 0 & $13(4.5)$ & $25(8.5)$ & $10(3.4)$ & $8(2.7)$ & $56(19.0)$ \\
Breast abscess & 0 & $16(5.4)$ & 0 & 0 & 0 & $16(5.4)$ \\
Galactocoele & 0 & $6(2.0)$ & 3 & 0 & 0 & $9(3.1)$ \\
Duct ectasia & $1(0.3)$ & $2(0.7)$ & 3 & $2(0.7)$ & 0 & $8(2.7)$ \\
Breast cysts & $2(0.7)$ & $4(1.4)$ & 0 & $1(0.3)$ & 0 & $7(2.4)$ \\
Atypical epithelial hyperplasia & 0 & 0 & 0 & 0 & $6(2.0)$ & $6(2.0)$ \\
Duct papillomas & 0 & $3(1.0)$ & $2(0.7)$ & $1(0.3)$ & 0 & $6(2.0)$ \\
Benign phylloides & $4(1.4)$ & 0 & 0 & 0 & 0 & $4(1.4)$ \\
Tuberculosis & 0 & $2(0.7)$ & $2(0.7)$ & 0 & 0 & $4(1.4)$ \\
Lipoma & 0 & 0 & $2(0.7)$ & 0 & 0 & $2(0.7)$ \\
Total & $13(4.5)$ & $198(67.1)$ & $52(17.6)$ & $18(5.1)$ & $14(4.7)$ & $295(100)$ \\
\hline
\end{tabular}

The majority of patients, 295(85.2\%) underwent surgical treatment of which lumpectomy was the most common surgical procedure performed (Table 4). The remaining patients were treated conservatively (by non-surgical approach) with reassurance, analgesics, antibiotics and patients with galactocele were also treated with anti-prolactin. Patients with tuberculosis of the breast were treated with antituberculous therapy.

Table 4: Distribution of patients according to the type surgical procedure performed $(\mathrm{N}=295)$

\begin{tabular}{lll}
\hline Type surgical procedure performed & Number of patients & Percentages \\
\hline Lumpectomy & 266 & 90.2 \\
Incision \& drainage & 16 & 5.4 \\
Microdectomy & 6 & 2.0 \\
Reduction mammoplasty & 4 & 1.4 \\
Other surgical procedures & 3 & 1.0 \\
\hline
\end{tabular}

\section{Discussion}

Globally, benign lesions of breast are the most common lesions which accounts for $90 \%$ of the clinical presentation related to breast (Murillo, 2002; Pollitt \& Gateley, 2004). In this study, benign breast diseases accounted for more than three quarters of all breast diseases seen at Bugando 
Medical Centre. This figure is comparable with other studies done elsewhere (Irabor \& Okolo, 2008; Kumar et al., 2010; Echejoh et al., 2011; Olu-Eddo et al., 2011; Okoth et al., 2013). The benign to malignant ratio in this study was calculated as 4.1: 1 which is similar to a ratio reported by Kumar et al (2010) in India, but at variance with the ratio reported in developed countries reflecting this to differences in public awareness regarding the disease (Guray \& Sahin, 2006).

The majority of patients in the present study were in the second and third decade of life and more than $90 \%$ of them were premenopausal. These findings are similar to those of other reports where patients presenting with benign breast disease were less than 30 years and typically in the 20-25 year age range (Guray \& Sahin, 2006; Echejoh et al., 2011; Olu-Eddo et al., 2011; Okoth et al., 2013). Similarly, the median age at presentation in our patient population was lower than that reported from developed countries (Guray \& Sahin, 2006). The reasons for the increase in the incidence of benign breast lesions in this age group is not clear but may be due to some physiological and pathological hormonal effects on the female breast as well as vulnerability to infection among lactating mothers due to poor hygiene.

In keeping with other studies (Memon et al., 2007; Echejoh et al., 2011; Olu-Eddo et al., 2011; Okoth et al., 2013 ), most of patients in the present study presented late to the health facility attributing this mainly to financial constraints and lump being painless. Other factors contributing to late presentation include hope that the lump may disappear, delayed referral to tertiary care facility, the lump does not interfere with normal duties and lack of awareness about the disease. The delay in presentation of breast lumps as compared with breast pain reported in this study suggests the need for appropriate health education to the population on the risk factors in breast cancer. In the current study, breast lump was the most frequent presentation which is in accordance with majority of the studies (Memon et al., 2007), but at variance with a recent study in India (Krishnaswamy et al., 2003) which reported that breast pain was present in more than half of patients while breast lump was present in about one-tenth of the patients. The incidence of breast pain in our study was similar to findings reported elsewhere (Adesunkami \& Agbakwuru, 2001; El-Wakeel., 2003; Ratanachaikamont, 2005; Navneet et al., 2012). The low incidence of breast discharge observed in our study has also been reported by Leis et al (1985). As reported in other studies (Kumar et al., 2010; Abhijit et al., 2013), the right breast was frequently affected in our study. This finding is at variance with Raju et al (1985) who found that the left breast was involved in the majority of cases. In present study, breast lumps commonly involved the upper outer quadrant which was in agreement with findings by other authors (Adesunkami \& Agbakwuru, 2001; Kumar et al., 2010; Navneet et al., 2012; Abhijit et al., 2013). We could not establish the reason for this anatomical site distribution.

Fibroadenoma was the most common benign breast disease in this study. Our finding was in agreement with most of the available literature on benign breast diseases (Ihekwaba., 1994; Greenberg et al., 1998; Adesunkami \& Agbakwuru., 2001; Mayun et al., 2008; Kumar et al., 2010). The peak incidence of fibroadenoma ranged from the 2 nd to the 3 rd decade of life, which was consistent with the findings of other studies (Adesunkami \& Agbakwuru., 2001; Mayun et al., 2008; Kumar et al., 2010; Abhijit et al., 2013). The reasons for the high frequency of fibroadenoma among females in this study are not clear. Demographic factors might play a role, considering the large number of young females within the population of these groups. The fibrocystic diseases were the second most common condition in our study and a majority of the patients belonged to the 3 rd and 4th decades. This concurs with findings by Nalwanga (2002) in Uganda who found that fibroadenoma was the most frequently diagnosed benign breast disease followed by fibrocystic diseases then breast abscesses. Fibrocystic disease is an important breast lesion because of its high frequency and the ability of some of its sub-types to mimic the clinical and radiographic appearance of carcinoma (Jeje et al., 2010). Hormones have been reported to play a role in its development but the exact pathogenesis still remains to be established (Jeje et al., 2010). Breast abscess ranked third and was more commonly seen in age group of 21-30 years. No case of breast abscess was seen below 20 years and above 30 years. The finding that most cases 
of breast abscess has also been reported by Khanzada et al (2009) in Pakistan. The increased incidence of breast abscess in most developing countries is related to poor hygienic conditions combined with breast feeding (Jeje et al., 2010). It appears that the figures for breast abscess in this study are underestimated because most breast abscesses are incised and drained without histopathological diagnosis. Moreover, most patients with breast abscesses are treated in the secondary centres and are not often referred to tertiary care hospitals such as ours.

In this study, one-fifth of breast benign diseases were proliferative in nature and just over a quarter of these had proliferative lesions with atypia. Similar findings have been reported elsewhere (Hartmann et al., 2006; Okoth et al., 2013). Previous studies indicate that atypical ductal hyperplasia and atypical lobular hyperplasia are proliferative lesions with atypia and therefore have premalignant potential (Dupont et al., 2006; Okoth et al., 2013). The risk of developing invasive carcinoma in the patients with benign proliferative breast lesions with atypia has been reported in different studies (Dixon \& Mansel, 1994; lyer, 2000; Hartmann et al., 2006; Dupont et al., 2006; Okoth et al., 2013).

Benign phylloides tumours have been described as rare fibroepithelial tumours that account for about $1 \%$ of all breast neoplasms (Parker \& Harris., 2001). Our patients with benign phylloides were aged below 20 years of age, similar to findings by Nzegwu et al. (2008) and Irabo \& Okolo (2011). However, our findings are in contrary to reports that this occurs in patients in their 50 s (Ohene-Yeboah, 2005). Phylloides can occasionally recur after excision, and also has a malignant variety. However, there was no recurrence in this study. Breast tuberculosis has been described as a rare modern disease in which diagnosis is rarely made without biopsy, the preoperative impression being carcinoma (Ikard \& Perkins., 1977; Hanif et al., 2002). In this study, all patients with tuberculosis of the breast were HIV positive reflecting increased risk of tuberculous breast diseases among HIV patients.

In conclusion, the spectrum of benign breast diseases in our study population does not appear to differ much from other studies with fibroadenoma being the most common benign breast lesions followed by fibrocystic changes. Benign breast disease in this population occurs mainly in young women less than 30 years of age. Though premalignant lesions of atypical hyperplasia were less common in this study, it is advisable that all cases of breast lesions should be carefully evaluated to exclude possibility of breast cancer.

\section{Acknowledgements}

The authors are grateful to all who participated in the preparation of this manuscript. Special thanks go to our research assistants for their support during data collection and in the management of our patients.

\section{References}

Abhijit, M.G., Anantharaman, D., Sumanth, B. \& Ranjani, R. (2013) Benign breast diseases: experience at a teaching hospital in rural India. International Journal of Research in Medical Sciences 1, 73-78.

Adesunkami, A.R. \& Agbakwuru, E.A. (2001) Benign breast disease at Wesley Guild Hospital, Ilesha, Nigeria. West African Journal of Medicine 20, 146-51

Devitt, J.E. (1986) Abandoning fibrocystic disease of the breast: Timely end of an era. Canadian Medical Association Journal 134, 217.

Dixon, J.M. \& Mansel, R.E. (1994) ABC of breast diseases. Symptoms assessment and guidelines for referral. British Medical Journal 309, 722-726.

Donegan, W. (2002) Common benign conditions of the breast. In: Donegan WL, Spratt JS, eds. Cancer of the Breast. $5^{\text {th }}$ edition. St. Louis, MO, Sanders. 67-110. 
Echejoh, G., Dzuach,i D., Jenrola, A. (2011)Histopathologic analysis of benign breast diseases in Makurdi, North Central Nigeria. International Journal of Medicine and Medical Sciences 3, $125-128$.

El-Wakeel, H.C. (2003) Systematic reviews of fibroadenomas as a risk factor on breast cancer. Breast 12, 302-07

Greenberg, R., Skornick, Y. \& Kaplan, O. (1998) Management of breast fibroadenomas. Journal of General Internal Medicine 13, 640-645.

Guray, M. \& Sahin, A.A (2006) Benign breast diseases: classification, diagnosis and management. Oncologist 11, 435-449.

Hanif, A., Mushtaq, M., Malik., K. \& Khan, A. (2002) Tuberculosis of breast. Journal of Surgery Pakistan 7, 26-28.

Hartmann, L.C., Sellers, T.A., Frost, M.H., Lingle, W.L., Degnim, A.C., Ghosh, K., Vierkant, R.A., Maloney, S.D., Pankratz, V.S., Hillmann, D.W., Suman, V.J., Johnson, J., Blake, C., Tisty, T., Vachon, C.M., Melton, L.J. \& Visscher, D.W. (2005) Benign breast disease and the risk of breast cancer. New England Journal of Medicine 353, 229-237.

Hught, T.S., Trudeau, M.E. \& Reyd, C.D. (1998) The diagnostic accuracy of fine needle aspiration cytology, physical examination and mammography in the diagnosis of palpable breast lumps. Cancer Journal of Surgery 42, 8-9.

Hutter, R.V.P. (1985) Goodbye to fibrocystic disease. New England Journal of Medicine 312, 179.

Ihekwaba, F.N. (1994) Benign breast disease in Nigerian women: a study of 657 patients. Journal of the Royal College of Surgeons of Edinburgh 39, 280-283.

Irabor, D.O. \& Okolo, C.A. (2008) An audit of 149 consecutive breast biopsies in Ibadan, Nigeria. Pakistan Journal of Medical Sciences 24, 257-62.

lyer, S.P. (2000) Epidemiology of benign breast diseases in females of childbearing age group. Bombay Hospital Journal 42, 10

Jeje, E.A., Mofikoya, B.O. \& Oku, Y.E. (2010) Pattern of breast masses in Lagos: a private health review of 189 consecutive patients. Nigerian Quarterly Journal of Hospital Medicine 20, 38-41.

Khanzada, T.W., Samad, A. \& Sushel, C. (2009) Spectrum of benign breast diseases. Pakistan Journal of Medical Sciences 25, 265-268.

Khemka, A., Chakravarti, N., Shah, S. \& Patel, V. (2009) Palpable breast lumps: Fine needle aspiration cytology versus histopathology, a correlation of diagnostic accuracy. Internet Journal of Surgery $18,1$.

Krishnaswamy, U. (2003) Profile of benign breast disease in the urban India. Indian Journal of Surgery $65,178-81$

Kumar, M., Ray, K., Harode, S. \& Wagh, D. (2010) The Pattern of Benign Breast Diseases in Rural Hospital in India. East and Central African Journal of Surgery 15, 59-64

Leis, H.P., Commarata, A. \& Laraja, R.D. (1985) Nipple discharge significant and treatment. Breast $11,6$.

Mande, N., Gakwaya, A.M., Byanyima, R.K. \& Othieno, F. (2004) The triple assessment in the preoperative evaluation of patients with breast cancer in Mulago Hospital, KampalaUganda. East and Central African Journal of Surgery 9, 111-116

Mayun, A.A., Pindiga, U.H. \& Babayo, U.D. (2008) Pattern of histopathological diagnosis of breast lesions in Gombe, Nigeria. Nigerian Journal of Medicine 17, 159-162

Memon, A., Parveen, S., Sangrarasi, A.K., Malik, A.M. \& Laghari, A. (2007) Changing pattern of benign breast lumps in young females. World Journal of Medical Sciences 2, 21-24.

Murillo, O., Botello, B., Hernandez., D., Ramirez-Mateos, C., Reynaga Garcia,. FJ. (2002) Benign breast diseases: clinical, radiological and pathological correlation. Ginecología y Obstetricia de México 2002; 70:613-8

Nalwanga, S. (2002) The pattern of benign breast diseases seen in Mulago Hospital. Thesis for $M$ Med in Surgery. Makerere University, Uganda. 
Navneet, K., Nitin, A., Pankaj, P. (2012) Clinicopathologic profile of benign breast conditions in Indian women. Prospective study based on aberrations of normal development and involution classification. World Journal of Surgery 36, 2252-58

Nzegwu, M.A., Adanna, A., Daniel, O, Ugochukwu, A, Agu, K. (2008) An unusually early age of presentation of Phylloides tumor in Eastern Nigeria. European Journal of Cancer Care 17, 312-3.

Ohene-Yeboah, M.O. (2005) An audit of excised breast lumps in Ghanaian women. West African Journal of Medicine 24, 252-5.

Okoth, C., Galukande, M., Jombwe, J. \& Wamala, D. (2013) Benign proliferative breast diseases among female patients at a sub Saharan Africa tertiary hospital: a cross sectional study. BMC Surgery 13:9.

Olu-Eddo, A.N., Ugiagbe, E.E. (2011) Benign breast lesions in an African population: a 25-year histopathological review of 1864 cases. Nigerian Medical Journal 52, 211-216.

Parker, S.J., Harris, S.A. (2001) Phyllodes tumors. Postgraduate Medical Journal 77, 4258-435.

Pollitt, J., Gateley, C.A. (2004) Management of benign breast diseases of the breast. Surgery 66, $164-8$.

Raju, G.C. \& Naraynsingh, V. (1985) Benign breast disease in a West Indian population. British Journal of Surgery 72, 17-18.

Raju, G.C., Jankey, N. \& Naraynsingh, V. (1985) Breast disease in young West Indian women: an analysis of 1051 consecutive cases. Postgraduate Medical Journal 61, 977-8

Ratanachaikamont, T. (2005) Clinical breast examination, palpable breast lesion. Journal of the Medical Association of Thailand 88, 505-07

Shaaban, A.M., Sloane, J.P., West., C.R., Moore, F.R., Jarvis, C., Williams, E.M. \& Foster, C.S. (2002) Histopathological types of benign breast lesions and risk of breast cancer. American Journal of Surgical Pathology 26, 421-430.

Srivatsava, A. \& Dhar, A. (2006) Benign Breast Disease: A neglected entity. Recent Advances in Surgery 10, 175-201.

Tavassoli, F.A., Devilee, P. (2003) World Health Organization histological classification of tumors of the breast in pathology and genetics of tumors of the breast and female genital organs. France: IARC; p. 10. 